Association for Information Systems AIS Electronic Library (AISeL)

ECIS 2007 Proceedings

European Conference on Information Systems

(ECIS)

2007

\title{
A Multiple Narrative Approach to Information Systems Failure: A Successful System that Failed
}

Estzer Bartis

Corvinus University of Budapest

Nathalie Mitev

London School of Economics

Follow this and additional works at: http://aisel.aisnet.org/ecis2007

\section{Recommended Citation}

Bartis, Estzer and Mitev, Nathalie, "A Multiple Narrative Approach to Information Systems Failure: A Successful System that Failed" (2007). ECIS 2007 Proceedings. 182.

http://aisel.aisnet.org/ecis2007/182

This material is brought to you by the European Conference on Information Systems (ECIS) at AIS Electronic Library (AISeL). It has been accepted for inclusion in ECIS 2007 Proceedings by an authorized administrator of AIS Electronic Library (AISeL). For more information, please contact elibrary@aisnet.org. 


\title{
A MULTIPLE NARRATIVE APPROACH TO INFORMATION SYSTEMS FAILURE: A SUCCESSFUL SYSTEM THAT FAILED
}

\author{
Estzer BARTIS, Corvinus University of Budapest, Hungary \\ Nathalie MITEV, London School of Economics, United Kingdom
}

\begin{abstract}
We discuss the introduction of an information system where the dominant coalition claimed project success. While the key users did not use the system as intended and the project goals were not achieved, the project committee reported success to the top management board. Using a multimethodological approach, we can follow how different stakeholders attributed different meanings to the system introduced over time. The rhetorical tools used are analysed using a narrative methodology. We draw on the social construction of technology and use the concept of relevant social groups to understand the different interests influencing the organizational dynamics. We complement this approach by employing the concepts of organisational power and cultural fit between the new system and the different subcultures. We found that this multiple approach explains well how the acceptance of the new software processes was interpreted differently within the organisation, and also by the software supplier. Although limited, our case study reveals the process of socially constructing the success or failure of an information system using this multiple research approach. We compare our results with the literature on IS failures and we consider the value of combining constructionist and critical approaches through a narrative methodology.
\end{abstract}

\section{INTRODUCTION}

IS failures have been surrounded by unabating interest in the last four decades. One main reason is that IT investments are expensive and of high risk (Carr 2003, Lyytinen \& Robey 1999, Fortune \& Peters 2005). Fitzgerald and Russo (2005) refer to the Standish Group’s survey reporting that only $16 \%$ of IS projects are completed on time and within budget. Sauer (1997) argues that to be more successful in the future, we have to understand and learn from failures, and Mitev (2000) that failures can reveal processes that would be hidden when systems are claimed to be successful. Some of the causes for failure have been identified as the difficulty to manage so many different factors (Sauer \& Southon 1997) or that organisations fail to learn (Lyytinen \& Robey 1999). Researching IS failures originates back in the 1960s. The early works were concerned with technological or engineering problems where systems were not delivering the required performance (Sauer 1997). These failures originated in hardware or software deficiencies. In the seventies, the focus turned towards user resistance and the lack of user involvement was quickly claimed to be a major reason for failure (Argyris 1971, Ein-Dor \& Segev 1978). Later, discussions also included managerial or organisational issues but were still resting on positivist assumptions. DeLone and McLean (1992) provide a thorough overview of the main research in the quest for the key success factors of that time. Some 10 years later DeLone and McLean (2003) discussed the critiques and suggestions and revised their model. Their work concentrates on positivist research applying quantitative methods. That means a stream of growing importance is left out of their work: interpretivist, constructionist and critical research, which use mainly qualitative methodologies. Epistemological approaches have therefore evolved and the focus of inquiries has broadened, taking into account wider organisational aspects. Mitev (2003) and Wilson and Howcroft (2002) summarise these more recent approaches and emphasise the lack of consensus, the multifaceted nature of IS and the subjectivity of the terms 'success' and 'failure'. White and Leifer (1986, p. 215) point out that "perceptions of a system's success or failure may vary depending upon an individual's perspective of the system" and Mitev (2000, p. 84) raises the justifiable question: "are there inherent differences between successful and unsuccessful [cases]?” Wilson and Howcroft (2005) 
adopt a social shaping approach showing that the empowered actors are able to turn the project into success: they stabilise the IS by overcoming resistance and enrolling the 'relevant social groups'. In many cases this is an ambiguous process. There are often some aspects of the system which clearly fail to fulfil expectations, but some actors still claim it a success - or on the contrary, a functionally working system could be abandoned because of user resistance (Pan 2005, Dhillon 2004). In such cases, the rationale often lies in the political processes of the organisation (Fincham 2002).

\section{MULTIPLE THEORETICAL CONCEPTS}

We first summarise the constructionist school to give a background to our general theoretical perspective. The social construction of technology (SCOT) provides the notion of the Relevant Social Group (RSG) which we used initially to analyse the case study. This was not sufficient to understand all the events and the full dynamics, so we combined it with a critical narrative methodology, which allowed us to go deeper in analysing the specific case material, and with which we were able to surface the notions of organisational power and cultural fit.

Constructionism has contributed to interpretive research on the multifaceted phenomenon of IS failures. Opposing technological determinism which suggests that technology has its own logic determining usage and development, social shaping (MacKenzie \& Wajcman 1999) and social construction of technology have become more prevalent in the IS field. Many different approaches and frameworks have emerged (Monteiro 2000) and they yield different insights on the interplay between IT and organisations. Bijker and Law (2000) identify several productive traditions, which correspond to different scientific backgrounds as well as theoretical approaches. Systems thinking (Hughes 1987) suggest that the relationship between technology and society is dynamically changing during the stages of technology. In the early stages of the development, a technological system will be shaped by society. When the technological system grows and develops, it will have more influence on society and it will begin to shape society (Dwyer 2001). By way of comparison, actor-network theory (ANT) is a more extreme constructivist approach and aims to develop a neutral vocabulary (Akrich \& Latour 2000) to describe the interactions of networked technical, social and economic elements. A heterogeneous actor-network contains people, objects and organizations which get aligned in a negotiation process. ANT has been criticized because of the move to grant artefacts the same explanatory status as human actors. On the other hand, the approach which we are adopting here, SCOT, is not so relativist but constructionist, and emphasizes the interpretative flexibility which is attributed to technological artefacts by different relevant social groups. It can also be combined with a critical approach more readily than ANT. Still, both SCOT and ANT transferred the focus of the sociology of scientific knowledge (Monteiro 2000, p. 74) to the opening of the black box of technological artefacts. Although these approaches differ both theoretically and methodologically, it is important to note that they complement each other (Bijker \& Law 2000).

One reason to use a social constructionist perspective is that "it emphasises a view of technological development as a social process thereby enabling and understanding how social factors shape technologies as well as providing a framework for understanding the context in which technologies are displaced" (Wilson \& Howcroft 2005, p. 18). Pinch and Bijker (1987) emphasise that 'relevant social groups' attribute meanings and problems to technical artefacts. This process results in interpretative flexibility: different social groups perceiving different problems will render different solutions to the 'same' technological artefact. Identifying homogeneous relevant social groups enables the discovery of a collection of different meanings and interpretations of the situation and of the technology. Also, conflicting viewpoints about how to resolve problems and use technology will be unfolded. Therefore, SCOT suggests that what is a success for someone can be a failure for someone else. As Wilson and Howcroft (2002, p. 239) argue, using the terms 'failure' and 'success' does not indicate "for whom the technology presents itself as such". Stabilisation of the artefact eliminates the different interpretations of problems (Pinch \& Bijker 1987, p. 44): "the key point is whether the relevant social groups see the problem as being solved”. 
An important critique of SCOT is that it focuses primarily on design rather than use, and it is assumed that after stabilisation, the interpretatively flexible period ceases and technology use becomes deterministic (Orlikowski 2000). A narrative approach enabled us to follow how rhetoric moves played a crucial role in the construction of different interpretations of use. Other IS researchers have stated that narratives are shared by individuals, acquiring common recognition as organisational 'stories' (Brown \& Jones 1998); According to Doolin (2003, p. 752) "any apparent stability is the result of more or less successful ordering attempts by various actors" and "organisation is performed in the language and practices" used by actors. He differentiates between the interpretive stream of narrative analysis, which sees language as a symbolic medium through which social reality is constructed; and the critical form of organisational narrative analysis which also includes with power (Doolin 2003, p. 755). Through our narrative analysis, which we will illustrate below, we found that rhetoric moves can be means of power and manipulation. This also corresponds to a deficiency with the notion of RSG in which the significance of the differences in power relationships does not get enough emphasis.

The dominant, non-critical, view in management studies is that only 'rational' behaviour can be legitimised in organisations and that must be consistent with rational purposes, thus excluding power and politics. Many scholars have identified, however, non-rational purposes as well: "[where] purpose is to appear as though they were intended to rationalize work or to improve decision making without having any real impact on organisational procedures or outcomes” (Markus 1983, p. 432). The political approach to organisations recognises the interplay of interests and conflicts of different coalitions in organisations. Power is a valuable resource in organisations (Markus, 1983) and is unequally distributed. However, organisational politics cannot be seen to drive behaviour explicitly as decisions cannot be legitimised with political motives based on group or individual interests. That results in a general dynamics in organisations where "actors observe prevailing norms of rationality by justifying action on rational grounds and honouring the appropriate organisational rules" (Wilson \& Howcroft 2005, p. 20). The sources of power are traditionally explained through the dependency of resources view (Pfeffer 1981). Power in organisations is an attribute of individuals or different groups of individuals (Markus 1983). According to Pfeffer (1992) the sources of power can be control over resources; control over or extensive access to information; and formal authority. These sources of power will be related to our critical narrative analysis.

IS embody a certain distribution of power, as information and control yield power, and any change in IS can result in changes in power relations. Changes in power relations trigger resistance among those who are loosing power. Organisational politics and power are considered to be of high impact on failure or success. Dhillon (2004, p. 635) argues that "inability to understand power relationships during systems analysis, design and implementation has serious implications (...) thus, it is a key factor in IS projects failure.” Pan (2005, p. 176) also states that "the main purpose is to identify stakeholders' roles, the conflicts that might exist among these roles, and the formation of any negative networks that could hinder project development.” Drawing from Markus (1983, p. 443) it will be suggested that the political variant is the most appropriate framework when: organisational participants disagree about the nature of the problem that a system is proposed to solve; there exists uncertainty about whether the particular proposed system will solve the problem; and the power bases allocated are highly valued and in short supply. Conversely, the SCOT perspective combines well with the power approach: focussing on stakeholders or coalitions (or 'relevant social groups') in an organisation is compliant with the organisational politics perspective. It is important to take into account the stakeholders' interests as implementing an information system "requires the effective participation of diverse stakeholders" (Pan 2005, p. 174). Different interpretations from the different stakeholders are formulated and spread in the organisation in the form of narratives.

Narratives are defined as a "tale, story, and recital of facts, especially story told in the first person" (Myers 1997). A narrative research methodology focuses on understanding how human beings deal with experience by constructing stories and listening to the stories of others (Riessman 1993). Researching narratives reveals the important insight that human activity and experience are filled with 
"meaning" and that stories rather than logical arguments or lawful formulations, are the vehicle by which that meaning is communicated (Sarbin 1995). The narrative perspective is a promising tool to observe the dynamics of rhetoric in organisations: the changing of the 'official' story over time. Narratives are frames for sense making focussing on symbolic and rhetorical aspects (Fincham 2002). Narratives also serve as social labelling, attributing sense-making categories to actions, events or artefacts. Behaviour and actions are influenced by sense making (Orlikowski \& Gash 1994), and sense making can be affected by narratives. Therefore, "the evolution of narrative sequences emphasizes the ways in which action is changed and influenced” (Fincham 2002, p. 2). We argue that narratives are tools for persuading organisational members (different RSG) and eliminating divergent interpretations, thus influencing stakeholders and building political coalitions, which fits in with the political perspective outlined above. Another important aspect influencing the behaviour of organisational members is the organisational culture, which is the last concept we are combining to our constructionist theoretical framework.

The concept of organisational culture and the fit of the newly introduced IS with the organisation's culture shed light on important aspects of the social dynamics surrounding an IS. Schein (1996, p. 236) defines organisational culture as "the set of shared, taken-for-granted implicit assumptions that a group holds and that determines how it perceives, thinks about, and reacts to its various environment." Organisational culture also manifests itself in visible ways (physical artefacts and behaviour); however, as it is based on deeper, hardly ever explicit assumptions, it is hard to change. All the assumptions "held by members of the organisation interrelate to form the culture that shapes decisionmaking processes and influences specific choices and behaviours” (Pliskin \& Romm 1993, p. 144). Many researchers (Claver \& Llopis 2001, Avison \& Myers 1995, Wainwright \& Waring 2004) claim that the consideration of organisational culture is somewhat neglected in IS research and practice. It is therefore important to include because in many failed system introductions, the organisational cultural fit is not considered (Gallivan 1997). Pliskin et al. (1993) suggest that important characteristics of the unique culture of the organisation should be considered prior to implementing new technologies. Based on empirical cases they conclude that there is a need for alignment between the taken-forgranted assumptions about work and organisation and the cultural assumptions embedded in the system by its designers. Ensuring the alignment of the IS and the organisational culture is even more difficult if it is designed and developed by a third party. The software vendor's designers build in their assumptions into the software features and routines.

SCOT is the main constructionist theoretical perspective used here, and through a critical form of narrative methodology we enrich it using the notions of power and organisational culture. Mitev (2005) has explored whether constructionist approaches are critical, and how they can be applied to studying IS success and failure. Constructionist approaches are critical in that they undermine the inevitabilism of accounts of technological success or failure; their contingency perspective questions the belief that socio-technical development can be controlled and managed. On the other hand, complementing a constructionist approach with a critical narrative methodology enables us to explore how actors are representatives of organisational agendas and how commercially-driven technical innovation can have political implications.

We show next how the different concepts used interact and form a solid and interlinked perspective. Constructionism is useful to follow firstly how initial ideas and opinions about the technology congeal (stabilisation); and secondly how powerful relevant social groups have a decisive influence when forming this quickly congealing public or group opinion. This is the point where the additional methodology of narratives proves useful. The different interpretations and 'stories' reveal that there are different interests and perspectives of relevant social groups. Exposing these alternative accounts sheds light on the process of the social construction of failure or success. Combining it with RSG, "it becomes possible to identify who contrives things such that their perspective is recounted as 'the' story" (Wilson \& Howcroft 2002, p. 239). In our analysis, we focus on the "purposive aspect" (Fincham 2002, p. 1) of the narratives which serve the interests of the RSGs. The narratives perspective highlights the dynamics of the 'official' explanation which creates, influences and 
manipulates public opinion. We will present different narratives from different relevant social groups at different times and analyse the discrepancies. The narratives also allow us to highlight the cultural differences between the culture embedded in the system and the organisational work culture. First, the dominant discourse in the organisation focuses on the taken-for-granted assumptions about work itself. The taken-for-granted assumptions are difficult to research as they manifest themselves in behaviour, rituals and values (Avison \& Myers 1995). Through some observation, we tried to draw conclusions regarding the characteristics of the culture. Secondly, we examine the organisational culture reasons for failure identified by Gallivan (1997): how different sub cultures were ignored leading to a lack of cultural fit.

We base our theoretical stance on constructionism, which we combine with a critical narrative methodology to examine how the meaning and the evaluation of the introduced system are socially constructed: (1) narratives influence the sense making process and people's understandings, and therefore, drive the construction of the common understanding; (2) organisational power as relevant social groups are constructing meaning, and the power relations between them; (3) organisational culture as the underlying assumptions shaping understandings and behaviour. These three facets were found to mutually influence each other and define the social construction of the evaluation and the usage of the introduced system.

\section{RESEARCH METHODS}

Primary data was collected on two different occasions and predominantly through qualitative methods. The first data collection was conducted inside the company during January and February 2006. The second collection was in June 2006 when the software vendor firm was visited and key users were interviewed again for validation and to review system acceptance. The case study is cross-sectional rather than longitudinal because some key project stakeholders moved into different positions, or left the company. Access to data was ensured through good personal relationships with the project manager, Anna (not her real name). She also provided rich data about the company culture and helped to get into informal discussions with employees involved in the project. Primary sources were semistructured interviews with the key actors including the project sponsor, the project owner, and managers and clerks from all departments involved. On the second occasion, we interviewed the supplier firms' managing director and the account manager. 22 semi-structured interviews and two focus group discussions were conducted in the two organisations (the software implementer and the vendor). Interviews lasted between 30 minutes and 2 hours. Participant observation also took place and documentary data was collected: handbooks, user instructions, and internal web pages. We had the opportunity to access the system, which provided a deeper understanding of the software's features and functions. Further important data was provided by informal conversations during factory and field visits. To complement qualitative methods, statistical data on the number of registered users and system usage were gathered. The company operates in Europe and names used are pseudonyms for confidentiality reasons.

\section{CASE STUDY}

In January 2004 Beta Company, a subsidiary of a large multinational FMCG company, decided to introduce a new work time registration (WTR) system. The country's regulations demanded that work time data are recorded daily and stored for 5 consecutive years. In any disputable case regarding working hours, these documents would constitute conclusive evidence. The project started in February 2004 and ran for eight months with no significant results delivered. Following the lay off of the former project manager, a new project manager was appointed early November 2004, and in 4 months the whole system was introduced step-by-step in all 14 locations countrywide. While the system could neither fulfil all the required functionalities, nor was the former paper-based administration eliminated (unlike the project's original goals), the project was still claimed as successful by the board of directors. Gamma was chosen as supplier, as it already operated the outsourced payroll system of Beta Company. In this service industry, Gamma was the largest in the country and with a good reputation. 
Full support in database maintenance and several Beta-specific developments were promised, but not included in the contract. A full outsourcing was decided with the servers and the data storage remaining outside Beta's firewall. The WTR system was to be accessed via a secure Internet connection. After the contract was signed, access to the system was ensured. In Beta three different pilot groups were set up to test processes and specific issues with usage. However, the feedback from the pilots was not systematically tracked by Beta, neither were the needed developments delivered by Gamma. As the WTR system was still not launched by November 2004, a new project manager was appointed and the former left the company.

In Beta, all employees' working hours and attendance are registered in the same work time registration system. However, the population of employees is far from homogeneous. Three main subgroups were identified during pilot testing. The main differences are: flexibility of working hours; planning and flexibility of holidays; wages/salary; hierarchical level; organisational culture (subcultures) and geographical location. The main groups are the manufacturing workers, the sales force and the management. The boundaries between groups are influenced by the location. For instance, managers working with the sales force or managers working in the factory tend to assimilate with the local subculture, although with differing interests. A main difference between different user groups can be epitomized by stating that wages workers had a basic interest in filling-in the data, while managers hadn't. For employees receiving wages and having little flexibility in working hours and holidays, the work-time registration and therefore, the system, played a pivotal role. It had a direct impact on the amount of money received monthly and, living close to subsistence wages, their livelihood was at stake. On the other hand, managers receiving a fixed salary and getting holidays fairly easily had no particular dependence on the data recorded in the system. As no significant punishments were compliant with the company culture, not filling-in the data had no consequences in the case of managers. Also, data accuracy demanded that wages workers record data daily or, in the worst case, weekly, while for managers, monthly recording was sufficient.

The 'official' narrative about the project changed over time and relates to different user groups' perceptions. Changes in the official narrative are illustrated below (together with the interviewee and date). When appointing the new project manager, she was told that the "only problem was about communication" (Project Sponsor, early November 2004) and that "everything is ready, pilot tests have been successful, all you need is to communicate the kick off date" (Former Project Manager, handover November 2004). After handover the HR Director (Project Sponsor) identified other issues: the affected databases were not linked and the steering committee knew only vaguely what was going on. Therefore, the official narrative changed to "you need to sort out a few technical problems" (Project Sponsor, mid-November, 2004). Gaining access to the system and receiving official training made clear to the project manager that user data had not been entered. The few users with access had forgotten their passwords and the last time they logged in had been June 2004. The project manager also realised that the user interface was not user-friendly and had a completely different inherent logic than other administrative systems in the company. Visiting the factory site, she identified user resistance problems, but the dominant problem was that no one could reliably handle the system. New training was organised and user instructions prepared and distributed. User resistance was almost eliminated when clerks and shift managers saw the project manager's efforts.

Following the next steering committee meeting, the official narrative changed completely: "this project is a terrible mess, we are so lucky to have Anna here to sort out all the issues" (Project sponsor, late November 2004). They were satisfied with her work and somewhat less concerned about the problems. However, the project manager realised that the pilot with the other critical group, the field force, had ceased because the manager trained had been promoted. Therefore, the new system had not been tested in that group with very special requirements. Still, at the next meeting, the Project Sponsor stated that it was impossible to delay the introduction any longer: "what do you think is the earliest we can start? Could you make it January?"(Project Sponsor, early December 2004). A compromise was reached on an incremental rollout: "we really needed quick wins to present it for the organisation and the people involved. That could also serve as a good example and help the next 
group to roll-in more smoothly" (Project Manager, early December 2004). The sequence of the rollout was decided based on the "reputation" of the units, i.e. how cooperative they were, so the rollout started at the factory's site.

Training and presentations were organised for different user groups. The data of the 250 factory employees were entered into the system and on $2^{\text {nd }}$ January the system was launched. Everything went right and people filled out their attendance sheets. The project manager sent a group email for the members of the steering committee reporting that everything went fine. Until the next day: as she turned on her mobile phone, messages and calls started: all data was lost from the system. Due to a problem in the server at the contractor, all work-time data had been lost. It caused delay in data processing and, of course, very low morale. The reasons were not acknowledged by Gamma, who blamed everything on the clerks at Beta. The project manager talking about the business relationship with Gamma stated that: "I believe they do not take us seriously. They thought we would never introduce the new system. I am surprised though as that is their business interest". The project manager added: "we not only had technical and trust problems with the outsourcing partner but low morale among employees. Still, the project had to go to save HR's face."

In February, the next stage in the rollout was management staff in head office. As they had flexible work-time, they needed just one click to indicate that they were not absent, however, the majority just forgot about it. Filling-in the timesheet was not their priority as they received a salary and were not paid for overtime. On the last days of the months, clerks usually went crazy seeing that no one had filled in their sheets. In March and April, the system was rolled out for the sales force working in remote depots. The technical problems experienced there were wide ranging: access to the site, loosing data, and the holiday-planner being unavailable. The servers were overloaded, as Gamma, after experiencing the delays with the launch, hadn't installed a more expensive server with sufficient capacity. Similarly, they never developed the promised holiday-planner; it remained a mock interface in the system.

Two important non-managerial user groups were the HR staff and the Supervisors, the latter responsible for planning shifts in the Manufacturing Division and in the Sales Department, and their daily work was significantly changed by the WTR system. They were involved in the pilot phase and gained initial training and access to the system. Also, the Sales Department had very special needs for planning and managing the routes and the work time of sales representatives. HR staff reacted to the system differently as some were leaving, some had to take over the work of the persons who left, and some took the task seriously and became experts: "we sat down with Anna for one whole day and went through all the functions. I took notes. As an unknown problem occurred, I called her immediately and we resolved it together. In my area, everybody fills in. I check the table the day before the deadline and send email warnings. It works." (HR administrator, January 2005). The others were not so successful and could not handle the system until as late as March: "I am working for two people; I do not have time to learn this new system. As far as I see it is quite stupid" (HR administrator, early March 2005).

The shift planners in Manufacturing did not take the system seriously as for a long time nothing happened to the system: "I have been filling in the system for a few months but nobody ever asked me or told me anything about it. I have not been doing it for a while now. We still use these big black books to register work time. Yes, manually. Every morning we check who showed up" (Shift Planner, early November 2004). When they had to start using the system: "planning people ask for machine usage. This system cannot store that kind of data, so now I have to fill in both manually and into the system. We have asked Anna to change the system and she promised that she talks to Gamma people. I hope it gets resolved soon, as I have to work double now..." (Shift Planner, mid December 2004). However, as Gamma was not making the requested developments (claiming that they were not paid), users got more and more worried and upset. During December and January, lost data was also reported. The clerks were complaining: "I have to work much more since this new system is here. I am entering the data, which is not easy at all, and suddenly the screen turns blue and all the data I entered is lost. It is VERY annoying. I discussed it with [my boss] and he said if these problems do not 
get resolved, we will return to the old system.” (Administrative Clerk, early February 2005). Gamma never acknowledged any problems and the Project Manager could not prove anything, being refused access to the log which was recorded by Gamma's system managers. The complaints from the Manufacturing site were never made official and the problems of the shift planners and clerks were overlooked.

The Sales Department was unintentionally left out from the pilot phase, which proved to be very problematic later. At the beginning, they took the system very seriously, and approached the Project Manager with their suggestions and ideas to improve the system. However, Gamma could not keep up the pace with the backlog, even after invoicing and payment issues were settled. "We told her [the project manager] what we need. The system is clearly unable to support our holiday planning and the substitutions which are both core activities. I am not using the system anymore. I've returned to Excel and every week I ask one of the guys to enter the data for the whole group" (Sales Supervisor, early April 2005). The Project Manager added in April 2005: "we had many discussions with Gamma people at all managerial levels. They promised the developments and mostly kept the deadlines. But we were simply not on the same page. They were unable and I think, also unwilling to understand that our organisation works differently from theirs. Solutions based on their processes and understandings will always be problematic and unproductive for us..."

The narratives of the non-managerial groups are different from one group to another. HR staff diverged in their approach, some had faith, putting effort into learning the new system, others just struggled through the reporting period. The manufacturing and sales groups were initially open towards the system and were willing to use it. After the first difficulties they still remained cooperative and either suggested solutions (Sales Department), or were willing to learn and understand the system (Manufacturing Department). However, after they saw that the situation did not improve, they chose alternative methods to keep track of the work time of their staff. The Sales Department returned to the cross-linked, fully functional Excel Sheets, while the Manufacturing Department kept using paper sheets to record the shifts. Gamma logged systems usage data which can be used as an accessible, objective and fairly simple indicator of user acceptance and system success (DeLone \& McLean 1992, p. 68). We carried out a quantitative log analysis, not reported in detail here, which shows that manufacturing workers and the sales force used the WTR system to fill in their work-time data, but that managers did not, and that their filling out rate dropped as time passed. As a result, HR clerks had to make huge efforts to collect all the data at the end of each month. It is suggested that for managers the system did not become part of their working routines for two reasons: they suffer no consequences for non-use; and using an irrelevant system once a month makes it too hard to remember how to use.

Hard work and tough high-level negotiations with Gamma led to several developments which resulted in the system's basic functions working. Shortly after, the project phase ceased as the Project Manager was needed in another project. Some functionality problems still remain; but HR administrators gained enough expertise to solve the frequently recurring problems. Officially, the project phase ended in June 2005. This meant that no manager was appointed to deal with problems and developments. According to the Project Manager, towards the end the steering committee "neither wanted to hear about WTR problems anymore, nor wanted to commit additional managerial time for solving problems". To summarise, the HR Director was keen for the system to be implemented, managers were non-users of the system for the reasons explained above, and never experienced the implementation problems experienced by wages workers who depended on the system for their livelihood. Manufacturing and sales staff initially had a positive attitude which then turned into disappointment and anger, and finally into resignation.

\section{ANALYSIS}

The RSGs have been described in the section above and their perceptions of the technology are first summarised below. Using a narrative methodology we then concentrate our analysis on the change of 
narratives over time. This enables us to bring out organisational power and politics, which we then extend into a discussion of the cultural fit between the system and the organisation.

There were important differences in the various RSGs' perceptions of the role of the WTR system. The HR Director wanted this 'messy, shameful' project to be finished quickly and all employees to enrol. Enrolment was not problematic for wages workers: the system had a direct impact on obtaining their monthly allowance, so recording their working hours was one crucial organising principle of their daily work. But for managers, their salary was fixed. So they did not attach importance to the administrative demand of filling-out their monthly presence sheets. Therefore, technical problems were of central importance for employees in lower hierarchical levels while most managers never logged-in and still received a salary. It is clear that different RSGs attributed different values to the technological artefact. The official narrative about the new system was mainly driven by the HR director and changed over time as shown below.

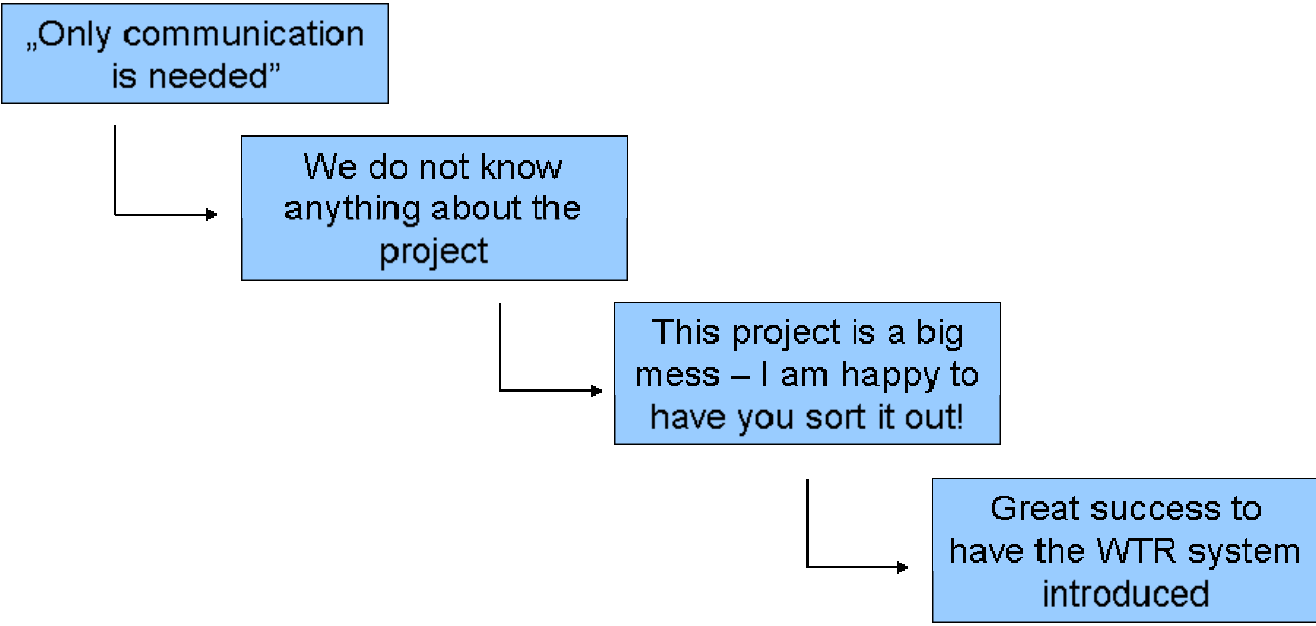

This can be compared to alternative narratives detailed in the previous section, showing how other key users perceived events. Comparing narratives allows us to distinguish power relations to explain whose interest and version became dominant. Implementing new software did not directly threaten positions or the status quo. The new system changed manual paper-based procedures to similar computer-based processes. As there was no change in locus or structure of information, no shift in power relations occurred. What was threatened, however, was the reputation of the HR Function and the HR Director. Organisational politics presented itself in a different way: face saving or the reputation of the HR Department was at risk. The project contract and the pilot were announced to the Board of Directors right at its launch, in January 2004, which was told that 'everything is fine' and was promised that 'very soon people will receive the WTR training'. As no progress was made for a long time after that, the HR Director's and the HR Department's reputations became threatened. This threat could only be warded off by implementing the system quickly. The success criterion was the system introduction and the proportion of enrolled users, almost regardless of the system quality or functionality. The dynamics can be explained further by examining how the sources of power were used by the HR Director. She used her power over resources when she laid off the former project manager and appointed a new one expecting improvements. Important was her control over access to information. She used it in two ways: (1) in the top management team nobody really knew about the problems with the system as no problems were let to get to that high level. Instead, she gave the Board the impression that everything was going well; (2) when problems started to arise, the HR Director used her power of agenda by influencing what questions were discussed at meetings. The evaluation of the WTR system was never on the agenda at higher level meetings. The fact that her agenda got prioritised and that her version became the official narrative were due to her formal authority. This analysis shows that identifying RSGs does not necessarily reveal power relations and neglects the 
inequalities in the possibilities of legitimising the interests of the different groups, which is achieved through the construction of narratives by actors. In our case, the identified RSGs were at different hierarchical levels. The power of clerks and factory workers cannot be compared to that of the HR Director.

In retrospect, it is clear that the initial narrative mainly served the purpose of 'selling' the project to the new project manager. On the other hand, as she recalls: "soon it became obvious that they hardly knew anything about the project. To be honest, I am sure they had no clue, what is done and what is not, or what could be the main concerns." To illustrate her feelings about the project: "now I could describe it, they sold me a project like a little ladybird which later turned into a huge hundred-armed monster. Not that I am complaining: this way I got a much better opportunity to prove my skills." Using the narrative methodology shows that the early mess and lack of results were manipulated, with little relation to any achievements by the new project manager. Building on the previous delays and struggling, it could be announced that the system was indeed introduced and used. This observation supports an important aspect of narratives, namely, that success and failure are not distinct notions but entwined in meaning and action (Fincham 2002).

The final stage of our analysis is to point out that two organisational subcultures at Beta had a strong influence on events, decisions and narratives. The wages workers regard work time registration as crucial to their living, but the managerial layer's salaries are fixed, so managers do not have any incentive to entering data. Initial decision makers neglected to consider this difference; judgements on the system desirability and success were made based on managers' perceptions; and the interest of the administrative clerks was never considered. The attitude of the software vendor Gamma mattered too. Its employees are dominantly software engineers and programmers. Management also has technical or engineering expertise. Gamma used WRT for their own work time registration. They often expressed opinions like: "I do not understand why it is difficult to record the work time data every day. One has simply to log on, fill in the daily data and save the changes. For me it takes a minute if not less" (Gamma Account Manager, late March 2005). They seem not to try to understand Beta's culture and saw its employees as problematic and unreliable. Conversely, the Beta project team thought Gamma were unwilling to help, rigid and uncooperative. Additionally, while the work of the HR administrators and administrative clerks at Beta doubled, Gamma received Beta payroll input data ready for their system ready for processing, thus reducing their costs. These differences between Beta's two internal subcultures and between Beta and Gamma organisational cultures explain how many problems evolved during system implementation, initial training, system maintenance and additional developments. Gamma was seemingly using its own perceptions while designing the WTR software whereas Beta's existing processes were rooted in their organisational culture (Schein 1996). Gallivan's notion of culture fit $(1997$, p. 243) helps identify the following reasons for the IS failure: the system was neglecting the incentives inherent in the worker's jobs; and there was no relationship between the users of the system and its beneficiaries; and the relationship between the designers and the users was fraught.

\section{DISCUSSION AND CONCLUSIONS}

We used a multiple narrative methodology to understand what happened in Beta. The social construction of technology is our theoretical premise reflecting our focus on how knowledge was constructed about technological success and failure. One of its concepts, relevant social groups, has already been used to investigate IS failure (Wilson \& Howcroft 2005). It was a good starting point to see how different RSGs attributed different meanings to the WTR system and, consequently, how different interests and problems arose. The narrative methodology exposed how different groups shaped the sense making. Used critically, it enabled us to surface the notion of organisational power in seeing why the narrative, meaning and interests of the more powerful RSGs prevailed. And the lack of fit between the new system and the organisational sub-cultures indicated why users were dissatisfied 
and the system under-utilised. It could not be resisted nor bypassed by certain groups for which use was unavoidable to get paid (paradoxically for those for whom it was most complex to use properly).

Although our present account may not provide a full narrative of the case, by exploring and comparing multiple narratives critically we found that there was a dominant narrative which turned the project into a success and thus inhibited any learning from the failures. In this case, there were numerous mistakes, defective analyses and rash decisions. Some of the potential learning points would have been: a new IT enabled business process needs to be specified and supported organisationally; the organisational cultures need to be taken into account; and piloting can yield important information which should not be ignored. Some of these have been expressed by the project manager and cooperating managers; but as these problems are not explicitly acknowledged, only directly affected employees have to deal with this difficult new system. And the lessons learned did not become organisational knowledge. As Weick (2001) points out, people only learn what they want: their observations are filtered through taken-for granted assumptions. No management-related learning points were made explicitly but the low-level administrative employees adapted their processes and behaviours to the new, ill-fitting system.

More broadly, the notion of RSGs showed that attributing success or failure was constructed differently by various groups. The narratives of the HR Director influenced the judgement of the top management who believed it was a success. But frequent users know that the system is dysfunctional and problematic. Their everyday experiences could not be changed by the official narrative. Understanding why a dysfunctional system not reaching its objectives was claimed as successful, the perspective of organisational power is unavoidable. The narratives perspective shed light on the system serving the power games, but in itself would be insufficient. If we focus on why the system was not accepted by the users, organisational cultural provides an additional explanation, and neither RSGs nor organisational power is sufficient. This shows the limitations of each methodological lens and how a multiple approach is beneficial, in this case combining constructionism and a critical narrative perspective, both of which treating reality as simultaneously social, technical and discursive (Doolin 2003, p. 766).

Finally, our study has the usual limitations: its generalisability and replicability, as well as the question of making sense of the sequences of events only ex post, when one would hope to prevent future failures. But every case is unique, and we are only able to use theories to the extent "to which data from real-world cases can be found to be consistent with the assumptions of the theories" (Markus 1983, p. 433). On the other hand, this case study draws similar conclusions about failure as Brown and Jones (1998, p. 85), although in reverse: in their failure case, they found that narratives tend to be "post-hoc rationalisations", "simplify the lessons to be learned" and "produce a coherent interpretation attributing cause [of failure] elsewhere"; in our case, the main narrative followed comparable patterns but about success. This confirms that similar processes are at work in organisational reports of success and failure, which addresses our initial research question hypothesising about the lack of inherent differences between successful and unsuccessful cases (Mitev 2000).

Several other aspects could have yielded additional valuable insights: the notion of project escalation (Keil 1995); the difficulties with early specification of requirements and the logic and structure of the software, which could also have been connected to the cultural fit; the dynamics of how the initial usage and experiences congeal fast (Tyre \& Orlikowski 1994); how usage is highly influenced by champions (Orlikowski et al. 1995); the initial understanding through taken-for-granted assumptions; and finally the inter-organisational politics to reveal the dynamics of the relationship with the supplier and the outsourcing difficulties. 


\section{REFERENCES}

Akrich, M. and Latour, B. (2000). A Summary of a Convenient Vocabulary for the Semiotics of Human and Nonhuman Actors. Shaping technology / Building society: studies in sociotechnical change. (Bijker, W. E. and Law, J.Ed.) Cambridge, Mass., MIT Press.

Argyris, C. (1971). "Management Information Systems: The challenge to rationality and emotionality." Management Science 17(6): B275-B292.

Avison, D. E. and M. D. Myers (1995). "Information systems and anthropology: an anthropological perspective on IT and organisational culture." Information Technology \& People 8(3): 43-56.

Bijker, W. E. and J. Law (2000). General Introduction. Shaping technology / Building Society: studies in sociotechnical change. (Bijker, W. E. and Law, J.Ed.) Cambridge, Mass., MIT Press: 1-13.

Brown, A.D. and Jones, M.R. (1998). "Doomed to Failure: Narratives of Inevitability and Conspirary in a Failed IS Project." Organization Studies 19(1): 73-88.

Carr, N. G. (2003). "IT doesn't matter." Harvard Business Review(May 2003): 41-49.

Claver, E., J. Llopis, et al. (2001). "The performance of information systems through organisational culture." Information Technology \& People 14(3): 247-260.

DeLone, W. H. and E. R. McLean (1992). "Information Systems Success: The Quest for the Dependent Variable." Information Systems Research 3(1): 60-95.

DeLone, W. H. and E. R. McLean (2003). "The DeLone and McLean Model of Information Systems Success: A Ten-Year Update." Journal of Management Information Systems (19): 9-30.

Dhillon, G. (2004). "Dimensions of power and IS implementation." Information and Management 41: 635-644.

Doolin, B. (2003). "Narratives of Change: Discourse, Technology and Organization." Organization 10:751-770.

Dwyer, J. (2001). Thomas Hughes, 'Technological Momentum', Opencopy.org. 2006.

Ein-Dor, P. and E. Segev (1978). "Organisational context and the success of management information systems." Management Science 24(10): 1064-1077.

Fincham, R. (2002). "Narratives of Success and Failure in Systems Development." British Journal of Management 13: 1-14.

Fortune, J. and G. Peters (2005). What is an information system failure? Information systems Achieving success by avoiding failure, John Wiley \& Sons, Ltd.: 13-28.

Gallivan, M. J. (1997). "The importance of organisational cultural fit: a technology implementation success story." International Journal of Failure and Lessons Learned in Information Technology Management 1(4): 243-257.

Hughes, T. P. (1987). The evolution of large technological systems. The Social Construction of Technological Systems. (Bijker, W. E., Hughes, T. H. and Pinch, T. J. Ed.) Cambridge, Mass., The MIT Press: 51-85.

Keil, M. (1995). "Pulling the plug: software project management and the problem of project escalation." MIS Quarterly 19(4): 421-447.

Lyytinen, K. and D. Robey (1999). "Learning failure in information systems development." Information Systems Journal 9: 85-101.

Markus, M. L. (1983). "Power, Politics, and MIS Implementation." Communications of the ACM 26(6): 430-444.

Mitev, N. (2000). Toward social constructivist understandings of IS success and failure: introducing a new computerized reservation system. International Conference on Information Systems, Brisbane, Queensland, Australia, Association for Information Systems.

Mitev, N. (2003). Constructivist and critical approach to an IS failure case study: Symmetry, Translation and Power. Working Paper Series, London School of Economics. London, June, 2003.

Mitev, N. (2005). "Are social constructivist approaches critical? The case of IS failure." In Handbook of Critical Information Systems Research: Theory and Application, Edited by D. Howcroft and E.M. Trauth, Edward Elgar, Cheltenham, UK, pp. 70-103.

MacKenzie, D., and Wajcman, J. (1999.). Introduction. The Social Shaping of Technology, 2nd Edition. Oxford, Oxford University Press. 
Monteiro, E. (2000). Actor-Network Theory and Information Infrastructure. From Control to Drift. ( Ciborra, C. Ed.). Oxford, Oxford University Press.

Myers, M. D. (1997). "Qualitative Research in Information Systems." MISQ Discovery 2(1): http://www.misq.org/discovery/MISQD_isworld/index.html.

Orlikowski, W. J. and D. C. Gash (1994). "Technological Frames: Making Sense of Information Technology in Organisations." ACM Transactions on Information Systems 12(2): 174-207.

Orlikowski, W. J., J. Yates, et al. (1995). "Shaping Electronic Communication: The Metastructuring of Technology Context in Use." Organization Science 6(4): 423-444.

Orlikowski, W. J. (2000). "Using technology and Constituting structures: A practice lens for studying technology in organisations." Organization Science 11(4): 404-428.

Pan, G. S. C. (2005). "Information Systems Project Abandonment: a Stakeholder Analysis." International Journal of Information Management 25: 173-184.

Pfeffer, J. (1992). Managing with power. Boston, Massachusets, Harvard Business School Press.

Pinch, T. J. and W. E. Bijker (1987). The Social Construction of Facts and Artifacts: Or How the Sociology of Science and the Sociology of Technology Might Benefit Each Other. The Social Construction of Technological Systems. (Bijker, W. E., Hughes, T. H. and Pinch, T. Ed.) Cambridge, Mass., The MIT Press: 17-50.

Pliskin, N., T. Romm, et al. (1993). "Presumed versus Actual Organisational Culture: Managerial Implications for Implementation of Information Systems." The Computer Journal 36(2): 143-152.

Riessman, C.K. (1993). Narrative Analysis. London: Sage.

Sarbin, T. R. (1995). A narrative approach to "repressed memories." Journal of Narrative \& Life History, 5, 41-66.

Sauer, C. (1997). Deciding the future for IS failures: not the choice you might think. Rethinking MIS. G. R. Currie W, Oxford University Press: 279-309.

Sauer, C., G. Southon, et al. (1997). Fit, failure, and the house of horrors: toward a configurational theory of IS project failure. International Conference on Information Systems, Atlanta, Georgia, United States, Association for Information Systems.

Schein, E. H. (1996). "Culture: The missing concept in organisation studies." Administrative Science Quarterly 41: 229-240.

Tyre, M. J. and W. J. Orlikowski (1994). "Windows of Opportunity: Temporal Patterns of Technological Adaptation in Organizations." Organization Science 5(1): 98-118.

Wainwright, D. and T. Waring (2004). "Three domains for implementing integrated information systems: redressing the balance between technology, strategic and organisational analysis." International Journal of Information Management 24: 329-346.

White, K. B. and R. Leifer (1986). "Information Systems Development Success: Perspectives from Project Team Participants." MIS Quarterly 10(3): 215-223.

Wilson, M. and D. Howcroft (2002). "Re-conceptualising failure: social shaping meets IS research." European Journal of Information Systems 11: 236-250.

Wilson, M. and D. Howcroft (2005). "Power, politics and persuasion in IS evaluation: a focus on 'relevant social groups'." Journal of Strategic Information Systems 14: 17-43. 